\title{
Exposure to airborne particulate matter during pregnancy is associated with preterm birth: a population-based cohort study
}

Emily DeFranco ${ }^{1,2^{*}}$, William Moravec ${ }^{2}$, Fan Xư ${ }^{3}$, Eric Hall', Monir Hossain ${ }^{4}$, Erin N. Haynes ${ }^{3}$, Louis Muglia ${ }^{1,2}$ and Aimin Chen ${ }^{3}$

\begin{abstract}
Background: Test the hypothesis that exposure to fine particulate matter in the air $\left(\mathrm{PM}_{2.5}\right)$ is associated with increased risk of preterm birth (PTB).

Methods: Geo-spatial population-based cohort study using live birth records from Ohio (2007-2010) linked to average daily measures of $\mathrm{PM}_{2.5}$, recorded by 57 EPA network monitoring stations across the state. Geographic coordinates of the home residence for births were linked to the nearest monitoring station using ArcGIS. Association between PTB and high $\mathrm{PM}_{2.5}$ levels (above the EPA annual standard of $15 \mu \mathrm{g} / \mathrm{m}^{3}$ ) was estimated using GEE, with adjustment for age, race, education, parity, insurance, tobacco, birth season and year, and infant gender. An exchangeable correlation matrix for the monitor stations was used in the models. Analyses were limited to non-anomalous singleton births at 20-42weeks with no known chromosome abnormality occurring within $10 \mathrm{~km}$ of a monitor station.

Results: The frequency of PTB was $8.5 \%$ in the study cohort of 224,921 singleton live births. High PM $_{2.5}$ exposure (>EPA recommended maximum) occurred frequently during the study period, with 24,662 women (11 \%) having high exposure in all three trimesters. Pregnancies with high $\mathrm{PM}_{2.5}$ exposure through pregnancy had increased PTB risk even after adjustment for coexisting risk factors, adjOR 1.19 (95\% Cl 1.09-1.30). Assessed per trimester, high $3^{\text {rd }}$ trimester $\mathrm{PM}_{2.5}$ exposure resulted in the highest PTB risk, adjOR 1.28 (95\% Cl 1.20-1.37).

Conclusions: Exposure to high levels of particulate air pollution, $\mathrm{PM}_{2.5}$, in pregnancy is associated with a $19 \%$ increased risk of PTB; with greatest risk with high $3^{\text {rd }}$ trimester exposure. Although the risk increase associated with high $\mathrm{PM}_{2.5}$ levels is modest, the potential impact on overall PTB rates is robust as all pregnant women are potentially at risk. This exposure may in part contribute to the higher preterm birth rates in Ohio compared to other states in the US, especially in urban areas.
\end{abstract}

Keywords: Air pollution, Particulate matter, PTB, Preterm birth, Prematurity

\footnotetext{
* Correspondence: emily.defranco@uc.edu

'Perinatal Institute, Cincinnati Children's Hospital Medical Center, Cincinnati, $\mathrm{OH}, \mathrm{USA}$

${ }^{2}$ Maternal-Fetal Medicine, Department of Obstetrics and Gynecology,

University of Cincinnati College of Medicine, 231 Albert Sabin Way, MSB

Room 4553B, Cincinnati, OH 45267-0526, USA

Full list of author information is available at the end of the article
} 


\section{Background}

Since the industrial revolution, it has become increasingly evident that environmental toxicants contribute to human disease. Air pollution is associated with several acute and chronic cardiopulmonary diseases. Particulate air pollution, in particular, has been found to be harmful in numerous studies, and was $9^{\text {th }}$ leading risk factor in the 2010 Global Burden of Disease Study [1]. Particulate air pollution is a heterogeneous group of airborne matter that ranges in size from a few hundredths of a micrometer to visible particles up to $100 \mu \mathrm{m}$. Combustion is the main source of harmful particulate matter (PM). Fine particulate matter $\left(\mathrm{PM}_{2.5}\right.$, referring to the upper limit of this fraction being $2.5 \mu \mathrm{m}$ ) has received much research and regulatory attention. As opposed to ultrafine particles - which are stable for only a short period of time, and coarse particles - whose travel is generally limited by the large size of the particles, $\mathrm{PM}_{2.5}$ can be both stable for long periods of time and are small enough to be distributed far from their source. $\mathrm{PM}_{2.5}$ comprises particles composed of hydrocarbons, organic compounds, ultrafine particle aggregates, biologic endotoxins, metals, and ions. Short-term exposure to $\mathrm{PM}_{2.5}$ can cause premature death, especially from cardiac and pulmonary disease. Long-term exposure to $\mathrm{PM}_{2.5}$ can also cause premature death from cardiac and pulmonary disease, but can also reduce lung development and lead to chronic respiratory diseases in children [2]. The EPA does monitor and set regulations for safe $\mathrm{PM}_{2.5}$ levels (www.epa.gov/ttn/naaqs/).

The connections between maternal toxin exposures and adverse birth outcomes is an emerging field of study that has begun to show that environmental toxicants are likely to be associated with some poor birth outcomes including stillbirth, low birthweight, some congenital anomalies, and preterm birth [3].

Several prior studies have reported the association between air pollutants and preterm birth, but report inconsistent findings of the association between preterm birth and increased $\mathrm{PM}_{2.5}$ levels [4-13]. Previous studies have been limited in design by exposures with measures at a single time point or with a lack of thorough adjustment for important clinical or socio-demographic risk factors. In this study we aim to integrate air quality measures from statewide monitoring stations with vital records to perform geospatial analyses testing the hypothesis that exposure to fine particles in the air $\left(\mathrm{PM}_{2.5}\right)$ is associated with preterm birth risk.

\section{Methods}

The Ohio Department of Health and Human Subjects Institutional Review Board approved a protocol for this study. This study was exempt from review by the Institutional Review Board at the University of Cincinnati, Cincinnati, Ohio. A data set generated from vital records of all live births that occurred in the state from 2007-2010 was provided for this analysis by the Ohio Department of Health, $n=597,000$.

This is a geo-spatial population-based cohort study. The primary exposure was high level of airborne $\mathrm{PM}_{2.5}$, fine particulate matter in the air measuring $<2.5 \mu \mathrm{m}$ in diameter. Trimester-specific and total pregnancy average daily $\mathrm{PM}_{2.5}$ levels were categorized as high exposure if the average over the specified time period was greater than $15 \mu \mathrm{g} / \mathrm{m}^{3}$, which was the EPA annual standard during the period of study. A secondary analysis was then performed modeling $\mathrm{PM}_{2.5}$ levels as a continuous variable. The primary outcome was preterm birth was defined as delivery prior to 37 completed weeks of gestation. Gestational age was defined by the best obstetric estimate variable in the birth record, which combines last menstrual period and ultrasound parameters, as is commonly accepted in clinical practice for gestational age estimation. Analyses were limited to non-anomalous singleton live births.

Daily measures of $\mathrm{PM}_{2.5}$, recorded by 57 monitoring stations across the state of Ohio, were obtained from the Environmental Protection Agency from 2007-2010 and monthly averages were calculated for each station [14]. Maternal address at time of birth was geocoded and distance to the nearest EPA monitoring station was calculated using ArcGIS 10.1 (ESRI, Redlands, CA) software. Births at gestational ages 20 to 42 weeks with a maternal home address within $10 \mathrm{~km}$ of an EPA $\mathrm{PM}_{2.5}$ monitoring station were included in this analysis ( $n=224,921$, Fig. 1$)$. Average monthly $\mathrm{PM}_{2.5}$ levels from the nearest EPA station were linked to the birth record data. Average $\mathrm{PM}_{2.5}$ levels for each trimester and an average for the entire pregnancy were calculated for each birth included in this analysis.

Demographic, medical and delivery characteristics of preterm live births ( $<37$ weeks) were compared to term live births (37-42 weeks) using $t$-test for continuous variable comparisons and $\chi^{2}$ tests for categorical variables. The association between preterm birth and high $\mathrm{PM}_{2.5}$ exposure was estimated using generalized estimating equations (GEE), with adjustment for the confounding influences of age, race, education, parity, insurance, tobacco, birth season and year, and infant sex. Odds ratios for high $\mathrm{PM}_{2.5}$ exposure during the first, second, and third trimester as well as high exposure averaged over the entire pregnancy were estimated from separate models with adjustment for all factors listed above. Covariates include in the models were chosen based on significant differences noted among bivariate comparisons, biologic plausibility, and parsimony within the model.

An exchangeable correlation matrix for the monitoring stations was used in the GEE models to account for 


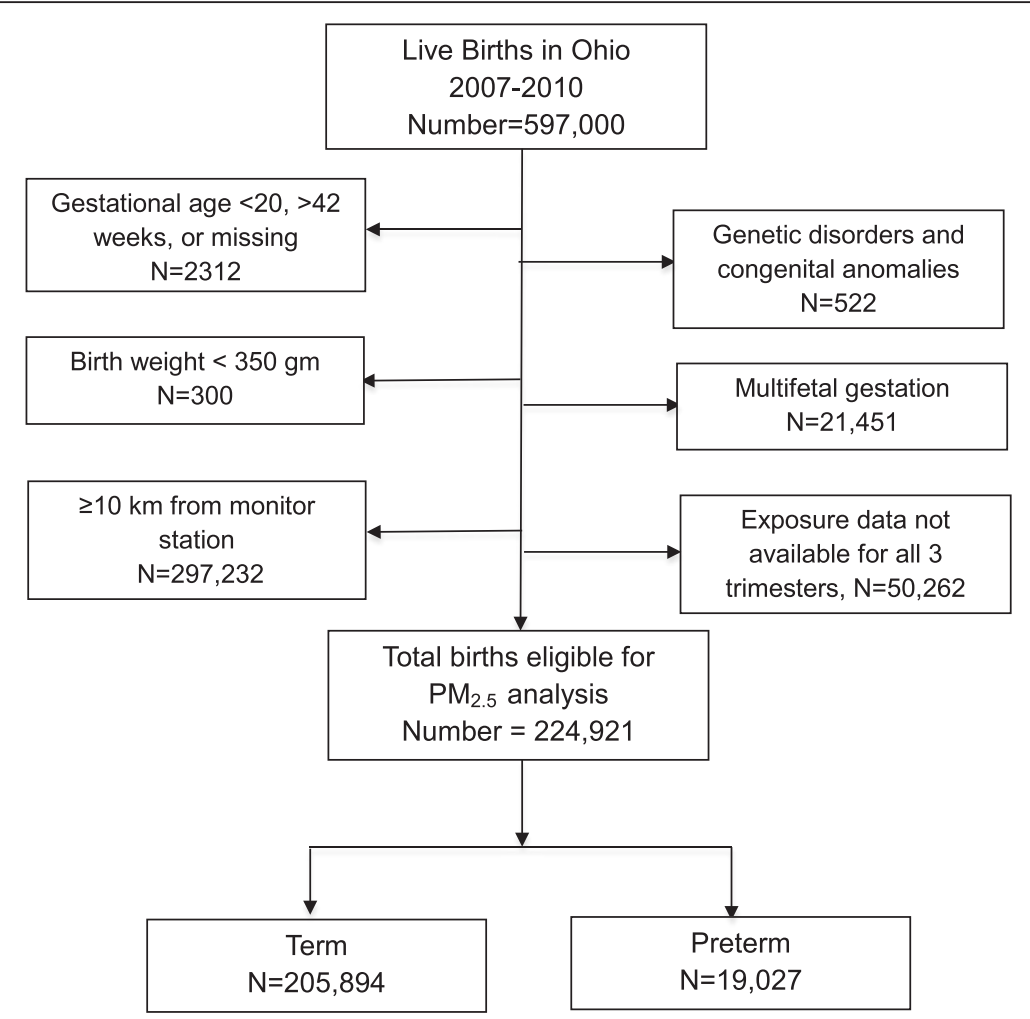

Fig. 1 Flow diagram of the study population, Ohio births 2007-2010

spatial correlation within the same $\mathrm{PM}_{2.5}$ monitor. Analyses were performed using SAS version 9.3, SAS Institute Inc., Cary, NC, USA. Comparisons with a probability value $<0.05$ or $95 \%$ confidence interval without inclusion of the null were considered statistically significant. Population attributable risk percentage (PAR\%) was calculated as: $\mathrm{PAR} \%=100 \times \mathrm{Pe}(\mathrm{RR}-1) /(\mathrm{Pe}(\mathrm{RR}-1)+1)$, where $\mathrm{Pe}$ is percentage of high exposure in the entire population (approximately $10 \%$ for the population included in this study) and RR is relative risk. Odds ratios approximate the relative risk in studies with an outcome rate of less than $10 \%$, as in this study. Therefore we utilized estimated odds ratios in lieu of relative risk in the PAR calculation. The PAR calculation inherently assumes a causal relationship, which is yet unproven in the association of particulate matter and preterm birth. With this in mind, we provide this calculation in effort to estimate the potential contribution of high $\mathrm{PM}_{2.5}$ exposure to preterm birth on a population level.

\section{Results}

The study population included 224,921 singleton nonanomalous live births: 19,027 preterm births and 205,894 term births, Fig. 1. The preterm rate decreased during the study period, from $8.6 \%$ in 2007 to $8.2 \%$ in 2010, Table 1. Most births analyzed (97\%) occurred in very urban areas, where most monitoring stations are located and exposure levels are likely to be highest. Preterm birth rates were higher among the oldest mothers, age $\geq 40$ years, $10.9 \%$, and non-Hispanic black mothers, $11.2 \%$, as well as women with lower education level and tobacco use. Women with no prenatal care had the highest rate of singleton preterm birth, $19.8 \%$. Season of conception had no influence on preterm birth rate.

The locations of $\mathrm{PM}_{2.5}$ monitor stations in Ohio and preterm births during the study period are demonstrated in Fig. 2. The mean $\mathrm{PM}_{2.5}$ level during the study period (2007-2010) in Ohio was $13.03 \mu \mathrm{g} / \mathrm{m}^{3}\left[ \pm 1.57 \mu \mathrm{g} / \mathrm{m}^{3}\right.$, IQR (Q1: 11.84, Q3: 14.13, IQR: 2.3)], which is higher than the current US EPA National Ambient Air Quality Standard (NAAQS) of $12 \mu \mathrm{g} / \mathrm{m}^{3}$. Mean $\mathrm{PM}_{2.5}$ level, IQR for the entire cohort per trimester was: $1^{\text {st }}$ trimester $13.19,2.36 \mu \mathrm{g} / \mathrm{m}^{3} ; 2^{\text {nd }}$ trimester $12.98,2.08 \mu \mathrm{g} / \mathrm{m}^{3} ; 3^{\text {rd }}$ trimester $12.93,2.30 \mu \mathrm{g} / \mathrm{m}^{3}$.

The frequency of high exposure to $\mathrm{PM}_{2.5}$ greater than the EPA standard of $15 \mu \mathrm{g} / \mathrm{m}^{3}$ ranged from 17 to $20 \%$ for each trimester of pregnancy, and $11 \%$ of parturients had high exposure throughout pregnancy in all three trimesters. The frequency of high $\mathrm{PM}_{2.5}$ exposure was higher in preterm births compared to term births, see Table 2. The preterm birth rate was also increased with high $\mathrm{PM}_{2.5}$ exposure during the first and third trimester, and when there was high $\mathrm{PM}_{2.5}$ exposure averaged over the entire pregnancy, as demonstrated in Table 3 . 
Table 1 Maternal Characteristics, Ohio 2007-2010

\begin{tabular}{|c|c|c|c|c|}
\hline & $\begin{array}{l}\text { Preterm (\%) } \\
N=19,027\end{array}$ & $\begin{array}{l}\text { Term (\%) } \\
N=205,894\end{array}$ & $p$-value & $\begin{array}{l}\text { Total births (\%) } \\
N=224,921\end{array}$ \\
\hline \multicolumn{5}{|l|}{ Demographic factors } \\
\hline \multicolumn{5}{|l|}{ Advanced maternal age } \\
\hline $35-39$ years & $1901(10.0)$ & $19,302(9.4)$ & $<0.01$ & $21,203(9.4)$ \\
\hline$\geq 40$ years & $482(2.5)$ & $3952(1.9)$ & & $4434(2.0)$ \\
\hline \multicolumn{5}{|l|}{ Race and ethnicity } \\
\hline Non-Hispanic White & $9940(52.7)$ & $127,636(62.6)$ & $<0.01$ & $137,576(61.2)$ \\
\hline Non-Hispanic Black & $7507(39.8)$ & $59,630(29.2)$ & & $67,137(30.1)$ \\
\hline Hispanic & $937(5.0)$ & $10,583(5.2)$ & & $11,520(5.2)$ \\
\hline Other & $457(2.4)$ & $6.116(3.0)$ & & $6573(2.9)$ \\
\hline \multicolumn{5}{|c|}{ Social behaviors \& socioeconomic factors } \\
\hline \multicolumn{5}{|l|}{ Education } \\
\hline Less than high school & $4778(25.4)$ & $40,658(19.9)$ & $<0.01$ & $45,436(20.4)$ \\
\hline High school graduate & $5127(27.3)$ & $50,721(24.9)$ & & $55,848(25.1)$ \\
\hline Some postsecondary & $8875(47.3)$ & $112,590(55.2)$ & & $121,465(54.5)$ \\
\hline Tobacco use & $4568(24.0)$ & $38,292(18.6)$ & $<0.01$ & $42,860(19.1)$ \\
\hline Medicaid insurance & $9672(50.8)$ & $87,631(42.6)$ & $<0.01$ & $97,303(43.3)$ \\
\hline \multicolumn{5}{|l|}{ Prenatal care initiation } \\
\hline First trimester & $8051(61.6)$ & $103,232(67.7)$ & $<0.01$ & $111,283(67.2)$ \\
\hline Second trimester & $3219(24.6)$ & $36,882(24.2)$ & & $40,101(24.2)$ \\
\hline Third trimester & $708(5.4)$ & $7897(5.2)$ & & $8605(5.2)$ \\
\hline No prenatal care & $1092(8.4)$ & $4422(2.9)$ & & $5514(3.3)$ \\
\hline \multicolumn{5}{|l|}{ Year of birth } \\
\hline 2007 & $5234(27.5)$ & $55,325(26.9)$ & 0.01 & $60,559(26.9)$ \\
\hline 2008 & $4969(26.1)$ & $52,708(25.6)$ & & $57,677(25.6)$ \\
\hline 2009 & $4600(24.2)$ & $50,364(24.5)$ & & $54,964(24.4)$ \\
\hline 2010 & $4225(22.2)$ & $47,497(23.1)$ & & $51,721(23.0)$ \\
\hline \multicolumn{5}{|l|}{ Season } \\
\hline Winter & $4755(25.0)$ & $50,205(24.4)$ & 0.26 & $54,960(24.4)$ \\
\hline Spring & $4787(25.1)$ & $51,827(25.2)$ & & $56,614(25.2)$ \\
\hline Summer & $4835(25.4)$ & $53,173(25.8)$ & & $58,008(25.8)$ \\
\hline Fall & $4650(24.4)$ & $50,689(24.6)$ & & $55,339(24.6)$ \\
\hline
\end{tabular}

Dichotomous variables for first 2 columns are presented as percent of total for each characteristic

Continuous variables are presented as median (IQR) for non-normally distributed data and mean +/- standard deviation for normally distributed data

Likewise, the mean $\mathrm{PM}_{2.5}$ levels during each trimester when compared between term and preterm pregnancies demonstrated significantly higher average $\mathrm{PM}_{2.5}$ levels during the first and third trimester for the preterm birth group compared to term births, $p=0.01$ (data not displayed in table). Likewise, the overall pregnancy average $\mathrm{PM}_{2.5}$ levels were higher for the preterm birth group compared to the term birth group, $p<0.01$.

Logistic regression models were constructed to identify factors associated with preterm birth. Factors with significant associations included maternal age $>35$,
non-Hispanic black race, Hispanic ethnicity, high school education or less, no prenatal care, tobacco use, high $\mathrm{PM}_{2.5}$ exposure during the third trimester, and high $\mathrm{PM}_{2.5}$ exposure over the entire pregnancy (Table 4 and Fig. 3). High $\mathrm{PM}_{2.5}$ levels $>15 \mu \mathrm{g} / \mathrm{m}^{3}$ during the third trimester or high when averaged over the entire pregnancy were associated with an increased risk of preterm birth $<37$ weeks of gestation, adjOR 1.28 (CI 1.20, 1.37) and adjOR 1.19 (CI 1.09, 1.30), respectively (Table 4). When $\mathrm{PM}_{2.5}$ exposure was modeled as a continuous variable in a secondary analysis, no significant association between exposure and preterm birth was 


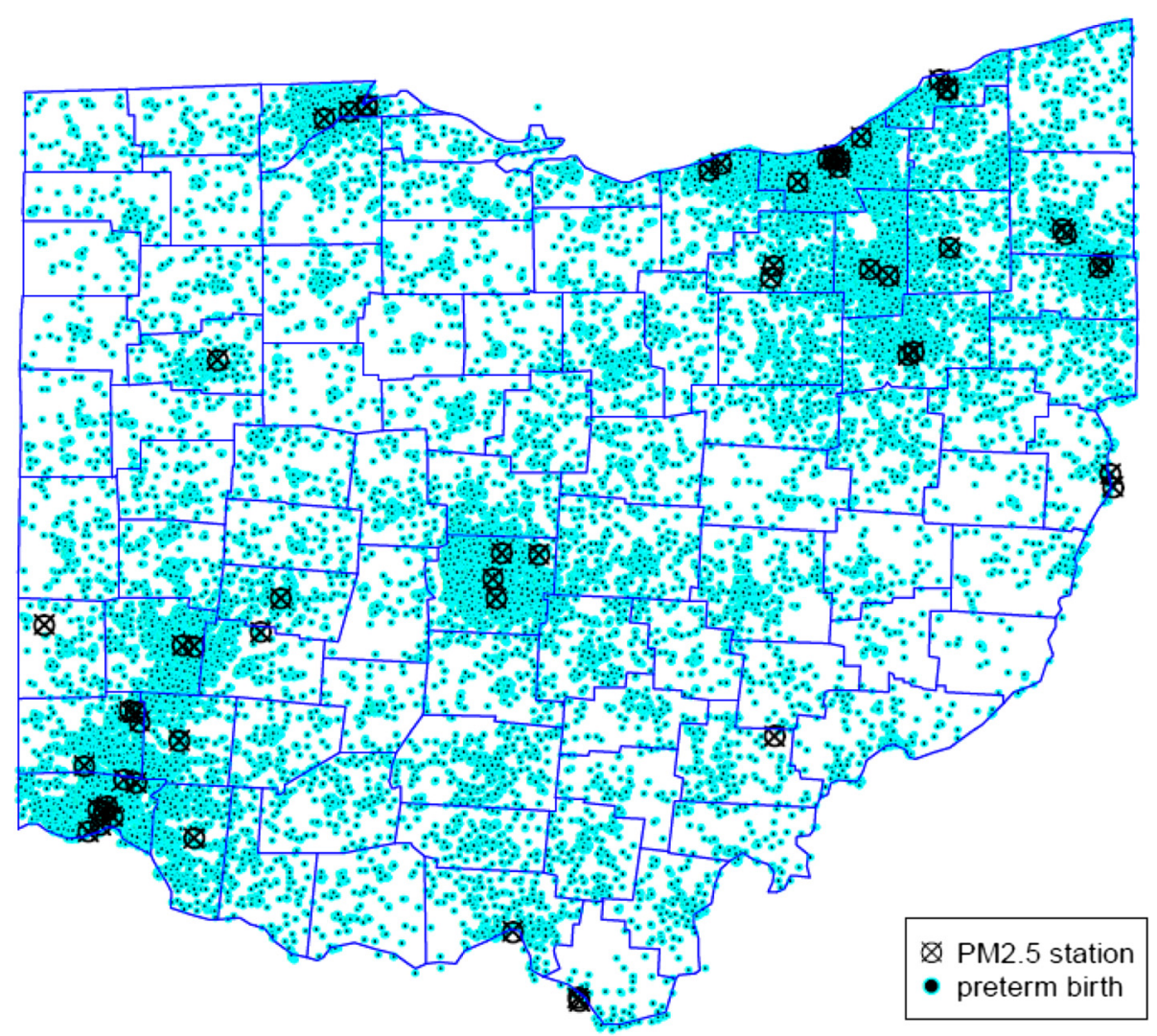

Fig. 2 Preterm births and $\mathrm{PM}_{2.5}$ monitoring stations in Ohio, 2007-2010

observed: adjOR 0.99 (CI 0.98, 1.00) for first trimester, adjOR 0.98 (CI 0.97, 1.00) second trimester, adjOR 1.0 (CI $0.99,1.00)$ third trimester, and pregnancy average adjOR 0.98 (CI 0.96, 1.0).

The attributable risk of preterm birth related to high $\mathrm{PM}_{2.5}$ exposure $>15 \mu \mathrm{g} / \mathrm{m}^{3}$ was $0.0172(95 \% \mathrm{CI}$ $0.0135-0.0208)$. The attributable risk percent: $(\mathrm{Ie}-\mathrm{Iu}) / \mathrm{Ie}$ is 17.18 (13.49 - 20.86) \%, i.e. for the exposed population, $17.18 \%$ of preterm births were from high $\mathrm{PM}_{2.5}$ exposure. In our study sample in which $10.96 \%$ of the population was exposed to high $\mathrm{PM}_{2.5}$, the population attributable risk percentage of high $\mathrm{PM}_{2.5}$ exposure was $2.22 \%$ for preterm birth.

\section{Discussion}

Our study adds to the growing body of evidence that particulate matter in the air is deleterious to human health. In our study sample, exposure to high levels of $\mathrm{PM}_{2.5}>15 \mu \mathrm{g} / \mathrm{m}^{3}$ was significantly associated with preterm birth - both when high exposure occurred on average over the course of pregnancy and with high exposure limited to just the third trimester. Our calculated attributable risk percent estimates that decreasing $\mathrm{PM}_{2.5}$ levels below this EPA standard threshold could theoretically decrease preterm birth by $17.18 \%$ in the exposed group, corresponding to a $2.22 \%$ decrease in preterm birth rate in the population.

Table $2 \mathrm{PM}_{2.5}$ levels in Ohio 2007 - 2010, by trimester of exposure in pregnancy and preterm status

\begin{tabular}{|c|c|c|c|c|}
\hline & $\begin{array}{l}\text { Preterm births } \\
N=19,027\end{array}$ & $\begin{array}{l}\text { Term births } \\
N=205,894\end{array}$ & & $\begin{array}{l}\text { All live births } \\
N=224,921\end{array}$ \\
\hline & $\% \mathrm{PM}_{2.5} \geq 15 \mu \mathrm{g} / \mathrm{m}^{3}$ & $\% \mathrm{PM}_{2.5} \geq 15 \mu \mathrm{g} / \mathrm{m}^{3}$ & $p$-value & $\% \mathrm{PM}_{2.5} \geq 15 \mu \mathrm{g} / \mathrm{m}^{3}$ \\
\hline First trimester & 22.97 & 21.81 & $<0.001$ & 21.91 \\
\hline Second trimester & 17.30 & 17.36 & 0.835 & 17.36 \\
\hline Third trimester & 22.84 & 18.90 & $<0.001$ & 19.23 \\
\hline Entire pregnancy & 12.94 & 10.78 & $<0.001$ & 10.96 \\
\hline
\end{tabular}

$\% \mathrm{PM}_{2.5} \geq 15 \mu \mathrm{g} / \mathrm{m}^{3}$ = percent of births in Ohio with average exposure level exceeding the EPA standard of $15 \mu \mathrm{g} / \mathrm{m}^{3}$ 
Table 3 Preterm birth rate by $\mathrm{PM}_{2.5}$ levels in Ohio 2007 - 2010 and trimester of exposure in pregnancy

\begin{tabular}{llllllll}
\hline & \multicolumn{2}{c}{$\mathrm{PM}_{2.5}<15 \mu \mathrm{g} / \mathrm{m}^{3}$} & & $\mathrm{PM}_{2.5} \geq 15 \mu \mathrm{g} / \mathrm{m}^{3}$ & \\
\cline { 2 - 3 } & $\mathrm{n}$ & $\%$ Preterm n & & $\mathrm{n}$ & $\%$ Preterm nn & $p$-value \\
\hline First trimester & 175,649 & 8.34 & & 49,272 & 8.87 & $<0.001$ \\
Second trimester & 185,883 & 8.47 & & 39,038 & 8.43 & 0.835 \\
Third trimester & 181,665 & 8.08 & & 43,256 & 10.05 & $<0.001$ \\
Entire pregnancy & 200,259 & 8.27 & & 24,662 & 9.99 & $<0.001$ \\
\hline
\end{tabular}

$\%$ preterm represents the rate of birth $<37$ weeks of gestational age among the study cohort of singleton non-anomalous live births

Table 4 Logistic regression of factors associated with preterm birth, Ohio 2007-2010

\begin{tabular}{|c|c|c|}
\hline & Adjusted odds ratio ${ }^{2}$ & $\begin{array}{l}95 \% \text { confidence } \\
\text { interval }\end{array}$ \\
\hline \multicolumn{3}{|l|}{ Maternal age, years } \\
\hline$<20$ & 0.93 & $0.84,1.02$ \\
\hline $20-24$ & 0.99 & $0.94,1.05$ \\
\hline $25-29$ & 1.00 & Referent \\
\hline $30-34$ & 1.04 & $0.97,1.10$ \\
\hline $35-39$ & 1.27 & $1.19,1.36$ \\
\hline$\geq 40$ & 1.52 & $1.37,1.69$ \\
\hline \multicolumn{3}{|l|}{ Maternal race } \\
\hline Non-Hispanic white & 1.00 & Referent \\
\hline Non-Hispanic black & 1.46 & $1.36,1.57$ \\
\hline Hispanic & 1.10 & $1.01,1.18$ \\
\hline Other Non-Hispanic & 1.02 & $0.88,1.18$ \\
\hline \multicolumn{3}{|l|}{ Maternal education level } \\
\hline Less than high school & 1.13 & $1.07,1.19$ \\
\hline High school only & 1.23 & $1.17,1.29$ \\
\hline Postsecondary education & 1.00 & Referent \\
\hline \multicolumn{3}{|l|}{ Prenatal care initiation } \\
\hline First trimester & 1.00 & Referent \\
\hline Second trimester & 0.97 & $0.94,1.01$ \\
\hline Third trimester & 0.94 & $0.85,1.05$ \\
\hline No prenatal care & 2.51 & $2.22,2.84$ \\
\hline Tobacco Use & 1.28 & $1.22,1.35$ \\
\hline \multicolumn{3}{|l|}{ High PM 2.5 exposure ${ }^{2}$} \\
\hline Average over pregnancy & 1.19 & $1.09,1.30$ \\
\hline First trimester & 1.02 & $0.97,1.07$ \\
\hline Second trimester & 0.96 & $0.90,1.01$ \\
\hline Third trimester & 1.28 & $1.20,1.37$ \\
\hline
\end{tabular}

1. Odds ratio estimates for covariates are adjusted for other factors listed in the first column of the table as well as parity, infant sex, year of birth, season of birth, and insurance type in the model with high average $\mathrm{PM}_{2.5}$ exposure over pregnancy 2. The odds ratio estimates for first, second, third trimester high Pm2.5 exposure are from separate models with adjustment for the same covariates as listed above

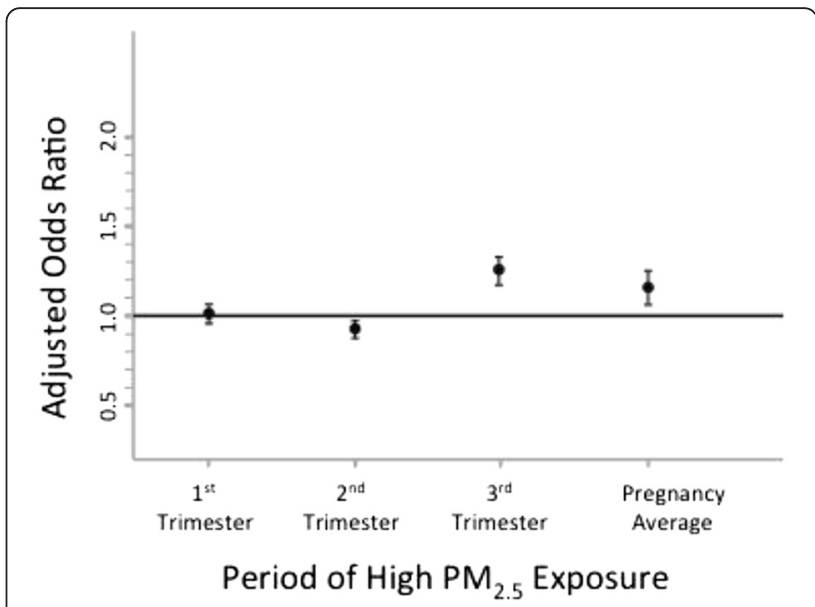

Fig. 3 Relative risk of preterm birth associated with exposure to high levels of $\mathrm{PM}_{2.5}$, by trimester of pregnancy, Ohio 2007-2010

An association between air pollution and preterm birth was first suggested in an analysis of the Nashville Air Pollution Study that showed increased risk of death in preterm infants whose mothers were likely to be exposed with high levels of particulate pollution [15]. Subsequent studies have further explored the link between preterm birth and other air pollutants using measurements of a variety of pollutants (TSP, SO2, NOx, $\mathrm{CO}$, and $\mathrm{PM}_{10}$ ) in proximity to maternal residence, measured by stationary or remote sensing satellite monitors. These studies demonstrated mixed results with regard to associations with preterm birth and timing of high exposure periods during the pregnancy [16-21].

Prior studies that have attempted to link preterm birth specifically to $\mathrm{PM}_{2.5}$ have also reported varied results. Gray et al. did not find significant effects in a study using EPA modeled data in North Carolina [6]. In a multi-country study, Fleisher found significant differences in preterm birth only in China when comparing areas with very high average $\mathrm{PM}_{2.5}$ levels $\left(>36.5 \mu \mathrm{g} / \mathrm{m}^{3}\right)$ compared to low levels $\left(<12.5 \mu \mathrm{g} / \mathrm{m}^{3}\right)$ [22]. Recent studies using satellite measurements have also been mixed: Rudra [23] found no effect, Gehring [5] found a nonsignificant trend toward increased risk of preterm birth with increased $\mathrm{PM}_{2.5}$ exposure, while Lee (2013) found high first trimester exposure was associated with modestly increased risk (OR 1.10 [1.01-1.20]) [24]. Jalaludin found that high $\mathrm{PM}_{2.5}$ levels associated only with risk of preterm birth in pregnancies conceived in the winter (OR 1.426) [25]. Kloog found an increased risk of prematurity using a model that incorporated measured and estimated exposure values (OR 1.06 (1.01-1.13) per $10 \mu \mathrm{g} / \mathrm{m}^{3}$ increase in third trimester) [9]. A recent metaanalysis combining previous studies found a modestly increased risk of preterm birth for each $10 \mu \mathrm{g} / \mathrm{m}^{3}$ increase in $\mathrm{PM}_{2.5}$ (OR 1.10 [1.03-1.18]); however, they 
did not find evidence of increased risk in trimester specific exposures, as we identified in this study [26].

The $\mathrm{PM}_{2.5}$ concentration threshold at which health is harmed is not well defined. We used the cutoff of $15 \mu \mathrm{g} / \mathrm{m}^{3}$ average to define high exposure as this was the EPA National Ambient Air Quality standard for annual mean levels of $\mathrm{PM}_{2.5}$ during the time period of the study. The standard was reduced to $12 \mu \mathrm{g} / \mathrm{m}^{3}$ in 2012 , after the EPA determined that the threshold level for harm may be in the $13-14 \mu \mathrm{g} / \mathrm{m}^{3}$ range [27]. We used the cutoff of $15 \mu \mathrm{g} / \mathrm{m}^{3}$ in these analyses because it may be more representative of exposure levels in relation to the EPA standard in our region during the time period of study. Using this threshold to define high exposure, we identified significant associations with preterm birth risk. However, when $\mathrm{PM}_{2.5}$ exposure was modeled as a continuous variable, no risk increase for preterm birth was identified. This may suggest a threshold effect in which a critical level of exposure is necessary before harmful health effects are seen.

There are multiple mechanisms by which particulate matter may lead to deleterious health effects. Three broad pathways exist that may explain how air pollution may affect organs outside of the lung: 1) Toxic substances may enter the blood via the lungs and be carried throughout the circulation. 2) There may be a systemic oxidative stress and inflammatory response that is either triggered in the lungs, or by substances once they gain access to the general circulation. 3) Toxicants may disrupt the autonomic nervous system causing imbalance of sympathetic and parasympathetic systems. There is evidence of the importance for each of these pathways at the cellular and molecular level in non-pregnant humans, especially related to cardiovascular events [28]. It is plausible that any or all of these mechanisms may contribute to alterations in uteroplacental perfusion, nutrient and oxygen transfer to the fetus, or stimulate the inflammatory response that commonly precedes the onset of preterm parturition.

There are a number of methodological limitations of our study, which are common to studies examining exposure to ambient air pollution and birth outcomes: 1) Specific pollutants and their ambient concentrations not considered independently but rather grouped as $\mathrm{PM}_{2.5}$. 2) Individual level exposure not quantified by personal sampling. Quantification of an individual's exposure is imprecise without either a completely controlled environment or portable sampling equipment - both of which are not practical for population cohort studies. 3) It is not known when the critical time for exposure is for specific outcomes. 4) Birth certificate data may not adequately describe potentially confounding socioeconomic or medical information. Regarding exposure quantification, there is likely some degree of sampling bias as EPA measurement stations are not randomly placed. Rather, monitoring sites are intended to capture ambient air levels and may be strategically placed to avoid major industrial sources of air, which could contribute to selection, and information bias. This misclassification could bias the results toward the null, and contribute to the lack of significant association identified when exposure was modeled in quartiles or as a continuous variable. Additionally, categorizing third trimester exposure as high levels occurring after 28 weeks would not account for early preterm births that occur prior to the third trimester. Despite statistical adjustment for available socioeconomic factors, unidentified socioeconomic factors or co-existent environmental risk factors may confound the interpretation of results in our study or similar studies. More populated areas tend to have higher proportions of patients with socioeconomic risk factors for preterm birth. Likely the best way to truly determine the connection between air pollution and preterm birth would be to have subjects carry continuous pollutant monitoring systems. This would allow more precise assessment of the threshold of risk and would allow us to further define behaviors associated with high pollutant exposure.

\section{Conclusions}

Our data suggest that women exposed to higher than the EPA standard exposure level of $\mathrm{PM}_{2.5}$ over the course of pregnancy are at increased risk for preterm birth. Based on trimester-specific high exposure periods, high exposure during the third trimester of pregnancy are also significantly associated with increased preterm birth risk. While this study does not precisely define a safe threshold for exposure, it does support the EPA's decision to decrease the standard exposure limit of $\mathrm{PM}_{2.5}$ concentration for individuals in the US. Additional research is needed to determine individual-level exposure as measured by ambient air and internal biomarkers of exposure and effect.

\section{Abbreviations \\ adjOR: adjusted odds ratio; CO: carbon monoxide; EPA: Environmental Protection Agency; GEE: generalized estimating equations; NAAQS: US EPA National Ambient Air Quality Standard; NOx: nitrogen oxide; OR: odds ratio; PAR: Population attributable risk; PM $_{10}$ : fine particulate matter, smaller than $2.5 \mu \mathrm{m} ; \mathrm{PM}_{2.5}$ : Fine particulate matter smaller than $2.5 \mu \mathrm{m}$; PTB: Preterm birth; RR: relative risk; SO2: sulfer dioxide; TSP: trisodium phosphate.}

\section{Competing interests}

The authors of this manuscript have no conflicts of interest or competing interests (financial or non-financial) to report.

\section{Authors' contributions}

Conceived and designed the study: ED MH EH AC ENH LM. Managed the data set including data preparation, performed data analyses and assisted with interpretation of the study findings: $\mathrm{FX}, \mathrm{EH}, \mathrm{MH}, \mathrm{AC}$. Analyzed the data: $F X, E H, M H, A C$. Contributed to writing and revising the manuscript: ED, WM, $\mathrm{FX}, \mathrm{EH}, \mathrm{MH}, \mathrm{ENH}, \mathrm{LM}, \mathrm{AC}$. All authors read and approved the final manuscript. 


\section{Acknowledgements}

This work was supported by the Perinatal Institute, Cincinnati Children's Hospital Medical Center, Cincinnati, Ohio, USA, and March of Dimes Grant 22-FY13-543 for the March of Dimes Prematurity Research Center Ohio Collaborative. The funding sources for this study were not involved in the design or conduct of the study; collection, management, analysis, and interpretation of the data; preparation, review, or approval of the manuscript. The decision to submit this manuscript for publication was made by the study authors without influence from the funding source.

This study includes data provided by the Ohio Department of Health which should not be considered an endorsement of this study or its conclusions.

\section{Author details}

'Perinatal Institute, Cincinnati Children's Hospital Medical Center, Cincinnati, $\mathrm{OH}$, USA. ${ }^{2}$ Maternal-Fetal Medicine, Department of Obstetrics and Gynecology, University of Cincinnati College of Medicine, 231 Albert Sabin Way, MSB Room 4553B, Cincinnati, OH 45267-0526, USA. ${ }^{3}$ Department of Environmental Health, University of Cincinnati College of Medicine, Cincinnati, OH, USA. ${ }^{4}$ Division of Biostatistics and Epidemiology, Cincinnati Children's Hospital Medical Center, Cincinnati, OH, USA.

\section{Received: 9 September 2015 Accepted: 10 January 2016}

\section{Published online: 15 January 2016}

\section{References}

1. Lim SS, Vos T, Flaxman AD, Danaei G, Shibuya K, Adair-Rohani H, et al. A comparative risk assessment of burden of disease and injury attributable to 67 risk factors and risk factor clusters in 21 regions, 1990-2010: a systematic analysis for the Global Burden of Disease Study 2010. Lancet. 2012;380(9859):2224-60.

2. Brook RD, Rajagopalan S. Particulate matter air pollution and atherosclerosis. Curr Atherosclerosis Rep. 2010;12(5):291-300.

3. Nieuwenhuijsen MJ, Dadvand P, Grellier J, Martinez D, Vrijheid M. Environmental risk factors of pregnancy outcomes: a summary of recent meta-analyses of epidemiological studies. Environ Health. 2013;12:6.

4. Brauer M, Lencar C, Tamburic L, Koehoorn M, Demers P, Karr C. A cohort study of traffic-related air pollution impacts on birth outcomes. Environ Health Perspect. 2008;1 16(5):680-6.

5. Gehring U, Wijga AH, Fischer P, de Jongste JC, Kerkhof M, Koppelman GH, et al. Traffic-related air pollution, preterm birth and term birth weight in the PIAMA birth cohort study. Environ Res. 2011;111(1):125-35.

6. Gray SC, Edwards SE, Schultz BD, Miranda ML. Assessing the impact of race, social factors and air pollution on birth outcomes: a population-based study. Environ Health. 2014;13(1):4.

7. Hannam K, McNamee R, Baker P, Sibley C, Agius R. Air pollution exposure and adverse pregnancy outcomes in a large UK birth cohort: use of a novel spatio-temporal modelling technique. Scand J Work Environ Health. 2014:40(5):518-30.

8. Huynh M, Woodruff TJ, Parker JD, Schoendorf KC. Relationships between air pollution and preterm birth in California. Paediatr Perinat Epidemiol. 2006;20(6):454-61.

9. Kloog I, Melly SJ, Ridgway WL, Coull BA, Schwartz J. Using new satellite based exposure methods to study the association between pregnancy PM2. 5 exposure, premature birth and birth weight in Massachusetts. Environ Health. 2012:11:40

10. Pereira G, Bell ML, Lee HJ, Koutrakis P, Belanger K. Sources of fine particulate matter and risk of preterm birth in connecticut, 2000-2006: a longitudinal study. Environ Health Perspect. 2014;122(10):1117-22.

11. Wu J, Ren C, Delfino RJ, Chung J, Wilhelm M, Ritz B. Association between local traffic-generated air pollution and preeclampsia and preterm delivery in the south coast air basin of California. Environ Health Perspect. 2009;117(11):1773-9.

12. Padula AM, Mortimer KM, Tager IB, Hammond SK, Lurmann FW, Yang W, et al. Traffic-related air pollution and risk of preterm birth in the San Joaquin Valley of California. Ann Epidemiol. 2014;24(12):888-95e4.

13. Ha S, Hu H, Roussos-Ross D, Haidong K, Roth J, Xu X. The effects of air pollution on adverse birth outcomes. Environ Res. 2014;134:198-204.

14. US Environmental Protection Agency. AirData. Available from: http://www. epa.gov/airdata/. Accessed 28 May 2015.

15. Sprague HA, Hagstrom R. The Nashville Air Pollution Study: mortality multiple regression. Arch Environ Health. 1969;18(4):503-7.
16. Xu X, Ding $H$, Wang $X$. Acute effects of total suspended particles and sulfur dioxides on preterm delivery: a community-based cohort study. Arch Environ Health. 1995;50(6):407-15.

17. Landgren O. Environmental pollution and delivery outcome in southern Sweden: a study with central registries. Acta Paediatr. 1996;85(11):1361-4.

18. Bobak M. Outdoor air pollution, low birth weight, and prematurity. Environ Health Perspect. 2000;108(2):173-6.

19. Ritz B, Yu F, Chapa G, Fruin S. Effect of air pollution on preterm birth among children born in Southern California between 1989 and 1993. Epidemiology. 2000;11(5):502-11.

20. Lin MC, Chiu HF, Yu HS, Tsai SS, Cheng BH, Wu TN, et al. Increased risk of preterm delivery in areas with air pollution from a petroleum refinery plant in Taiwan. J Toxic Environ Health A. 2001;64(8):637-44.

21. Liu S, Krewski D, Shi Y, Chen Y, Burnett RT. Association between gaseous ambient air pollutants and adverse pregnancy outcomes in Vancouver, Canada. Environ Health Perspect. 2003;111(14):1773-8.

22. Fleischer NL, Merialdi $M$, van Donkelaar $A$, Vadillo-Ortega F, Martin RV, Betran AP, et al. Outdoor air pollution, preterm birth, and low birth weight: analysis of the world health organization global survey on maternal and perinatal health. Environ Health Perspect. 2014;122(4):425-30.

23. Rudra CB, Williams MA, Sheppard L, Koenig JQ, Schiff MA. Ambient carbon monoxide and fine particulate matter in relation to preeclampsia and preterm delivery in western Washington State. Environ Health Perspect. 2011;119(6):886-92.

24. Lee PC, Roberts JM, Catov JM, Talbott EO, Ritz B. First trimester exposure to ambient air pollution, pregnancy complications and adverse birth outcomes in Allegheny County, PA. Matern Child Health J. 2013;17(3):545-55.

25. Jalaludin B, Mannes T, Morgan G, Lincoln D, Sheppeard V, Corbett S. Impact of ambient air pollution on gestational age is modified by season in Sydney, Australia. Environ Health. 2007;6:16.

26. Zhu X, Liu Y, Chen Y, Yao C, Che Z, Cao J. Maternal exposure to fine particulate matter (PM2.5) and pregnancy outcomes: a meta-analysis. Environ Sci Pollut Res Int. 2015;22(5):3383-96.

27. National Ambient Air Quality Standards for Particulate Matter; Final Rule, Fed. Reg. Vol. 78, No. 10 (January 15, 2013) (to be codified at 40 CFR Parts 50, 51, 52, 53, and 58). Print. www.gpo.gov/fdsys/pkg/FR-2013-01-15/pdf/ 2012-30946.pdf. Accessed 28 May 2015.

28. Brook RD, Urch B, Dvonch JT, Bard RL, Speck M, Keeler G, et al. Insights into the mechanisms and mediators of the effects of air pollution exposure on blood pressure and vascular function in healthy humans. Hypertension. 2009:54(3):659-67.

\section{Submit your next manuscript to BioMed Central and we will help you at every step:}

- We accept pre-submission inquiries

- Our selector tool helps you to find the most relevant journal

- We provide round the clock customer support

- Convenient online submission

- Thorough peer review

- Inclusion in PubMed and all major indexing services

- Maximum visibility for your research

Submit your manuscript at www.biomedcentral.com/submit
Biomed Central 